\title{
Research and Design of Streetlight Lamp Pole Automatic Cleaning Device
}

\author{
Mengyu Fu \\ North China Electric Power University Baoding, Baoding 071003, China \\ 437514235@qq.com
}

\section{Keywords: Streetlight; Lamp pole; Clean; Robot}

\begin{abstract}
Point at the series of drawbacks on those traditional manual cleaning methods, a new streetlight lamp pole automatic cleaning device is put forward. This device possesses the features of high efficiency, low energy consumption, low cost and convenient operation. The main body of the lamp pole cleaning device intend to adopts an upper and lower ring structure which is connected by a ball hinge joint. The upper ring is used to drive and the lower ring is used to scrub. The driving ring adopts a wheel structure. The use of automatic cleaning device may become a revolution in the cleaning industry, which will further promote the construction of smart city. Great economic and social benefits will appear along with its development.
\end{abstract}

\section{Introduction}

As an indispensable part of urban construction, streetlight can not only be used for illumination in the night, but also show the local characteristics and beautify the urban environment because of its unique design and beautiful appearance. The height of street lamp is usually $6 \sim 12$ meters. The lamp pole is made of steel whose surface is painted or treated by electroplating process. Because the street lamp is exposed in the atmosphere all the year round, the wind blown sand will lead to the dust accumulation in its surface area. This will affect the city appearance. At the same time, if the air mixed with acidic material attach to the lamp surface, it will accelerate the rust of the metal material and reduce the service life of the lamp. Therefore, it is necessary to carry out the cleaning and maintenance of street lamp poles. Some international cities such as Shenzhen and Xiamen even have a rule to wash at least several times a year.

At present, the street lamp cleaning work mainly depends on manual cleaning which means cleaning workers are sent to the height for cleaning scrub by lifting cars or the workers flush the lamp pole with high-pressure water cannons on the ground. These two methods are both plagued by problems. The former is confronted with not only inefficiency but also high cost of labor and equipment. The staff have to do high-altitude operations under the sun, wind and other extreme weather, and personal safety is threatened. The latter will waste a lot of water resources. And high-pressure water cannons can not be used around the vehicle and pedestrians pass. This method has a obvious impact on the surrounding environment, which is very inconvenient.

A streetlight lamp pole automatic cleaning device is urgently needed to deal with the series of drawbacks. This device must possess the features of high efficiency, low energy consumption, low cost and convenient operation, which can easily reach the lamp height and automatically complete the cleaning work of the lamp pole. The use of automatic cleaning device may become a revolution in the cleaning industry, which will further promote the construction of smart city. Great economic and social benefits will appear along with its development.

Although the needs of lamp automatic cleaning is put forward early, the traditional manual cleaning methods is difficult to be replaced because it's difficult for just a device to complete cleaning work in large numbers and urban management or other departments concerned purchase a large number of such smart devices costly. That's the reason why the pole automatic cleaning device have no effective product at present.

As the robot industry has gradually been the most widely used and the most rapidly developing high-tech industry in contemporary, robots which are similar with the pole automatic cleaning 
device in terms of function and structure emerge in large numbers such as climbing robot, pipeline climbing robot and glass curtain wall cleaning robot etc.

Climbing robot is an important branch of the robot family. Comparing with the ground mobile robot, the most obvious difference is that it needs to overcome gravity to move and complete the works in specific conditions reliably attached to the climbing surface[1]. The wall climbing robot's research began firstly. This kind of robot is mainly used in high-rise buildings, hydroelectric dam surface and large spherical surface to do dangerous operations. As early as in 1966, the first vertical wall mobile robot prototype was developed in Japan. After that, Russia and Japan have also developed wall climbing robots with sucker; the British developed a multi-legged wall climbing robot with suckers on its leg end and abdomen; America developed a vacuum adsorption type tracked wall climbing robot and robot prototype with the four leg-wheel. Since 1988, Harbin Institute of Technology has successfully developed a magnetic adsorption wall climbing robot [2].
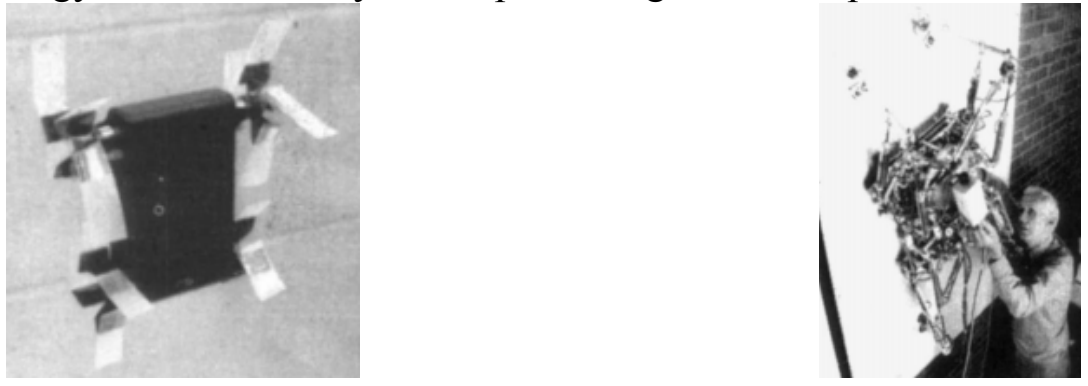

Figure 1. British multi-legged climbing robot Figure 2. American leg-wheel climbing robot

At present, the automatic crawling mechanism attached to the surface of the rod body proposed at home and abroad mainly includes electric mechanical robot and pneumatic worming robot [3, 4]. The electric mechanical has a high requirement for the working resistance and the dead weight of the robot. The pneumatic worming robot needs to be equipped with air supply and pneumatic control system, which is costly.

The inner and outer tube surface is the two development direction of the development of the pipeline robot. For the climbing robot on the outer surface of the pipe, there are many types of wheel, multi-joint, parallel [5] and so on. The modular bionic robot model established by South China University of Technology and the step type pipeline crawling mechanism developed by Beijing Institute of Technology are on behalf of multi-joint type pole climbing robot [6].

As a special kind of intelligent service robot, its market budget can be up to one hundred billion only in Europe [7]. For different cleaning target, cleaning technology and operation mode of the robot are different. The main types include suction, scrub, jet, scratch and shovel [8]. Japan, the United States, the United Kingdom all have certain research results in the term of wall cleaning robots. The German airline company developed a "Cleaning giant" used for aircraft cleaning. Israel SkyBot corp developed an integrated cleaning robot. The domestic representative productions are high-pressure water jet on-line cleaning robot for power plant condenser [9] and the series of robot developed by Beijing University of Aeronautics and Astronautics called Washman [10] and so on.

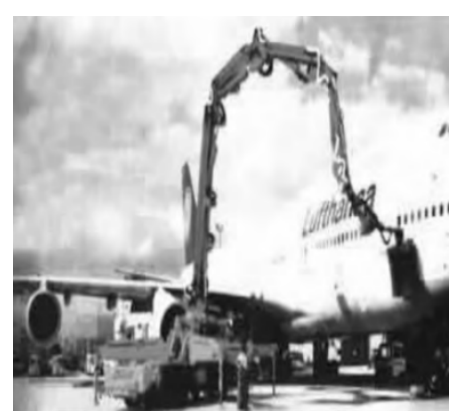

Figure 3. Cleaning giant

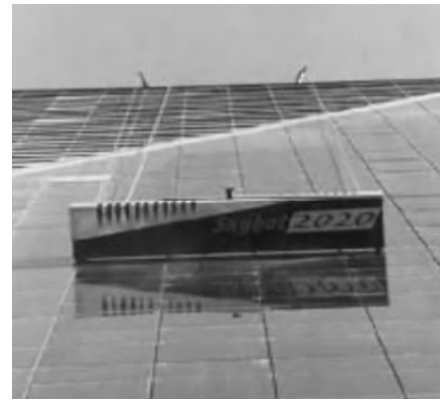

Figure 4. SkyBot's cleaning robot 


\section{Function Principle Design}

Combined with the research background mentioned above, a kind of automatic cleaning device for street lamp is designed, which mainly includes crawling and cleaning:
A. can clean the different height of the lamppost and high efficiency;
B. can adapt to different diameter and diameter of the road lamp;
C. cleaning efficiency and effectiveness can be adjusted according to motor speed;
D. crawling action is stable;
E. simple structure, easy to use and maintain.

The black box theory is a kind of scientific method to analyze the function and characteristic of black box and to explore its structure and mechanism based the use of external input and output characteristics [11].This method is adopted to determine total function of device.

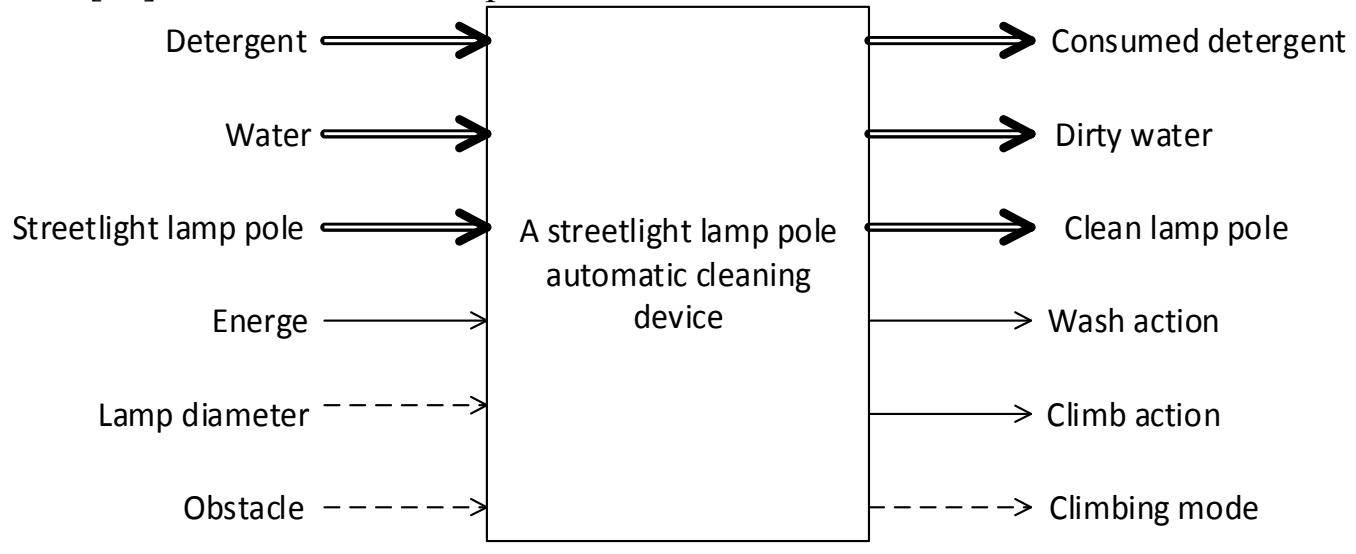

Figure 5. Black box schematic

The solution of the function is to seek the technical entities to complete the function, functional carrier. Beginning with the general scientific principles of basic research, the application of research can find out the specific principles, and then seek to achieve the technical principles of the technical means and the main structure.

Table 1 Morphological matrix

\begin{tabular}{|c|c|c|c|c|c|}
\hline \multirow{2}{*}{ Function element } & \multicolumn{5}{|c|}{ Function element solution } \\
\hline & 1 & 2 & 3 & 4 & 5 \\
\hline A.Linear movement & Wheel & Joint & Cylinder & Parallel & Base \\
\hline B.Turn & Differential & $\begin{array}{l}\text { Steering } \\
\text { mechanism }\end{array}$ & $\begin{array}{l}\text { Energy to } \\
\text { turn }\end{array}$ & & \\
\hline C.Locked in place & $\begin{array}{l}\text { Magnetic } \\
\text { adsorption }\end{array}$ & $\begin{array}{l}\text { Vacuum } \\
\text { adsorption }\end{array}$ & $\begin{array}{l}\text { Power } \\
\text { clamping }\end{array}$ & $\begin{array}{l}\text { Mechanical } \\
\text { clamping }\end{array}$ & \\
\hline $\begin{array}{l}\text { D.Supply water and } \\
\text { detergent }\end{array}$ & $\begin{array}{l}\text { Pipeline } \\
\text { transportation }\end{array}$ & $\begin{array}{l}\text { Storage } \\
\text { warehouse }\end{array}$ & $\begin{array}{l}\text { Supply } \\
\text { device }\end{array}$ & & \\
\hline E.Washing & Brush & Rinse & Scrub & Ultrasonic & $\begin{array}{l}\text { Vacuum } \\
\text { suction }\end{array}$ \\
\hline F.Start and stop & Key control & $\begin{array}{l}\text { Remote } \\
\text { control }\end{array}$ & $\begin{array}{l}\text { Acquire } \\
\text { signal }\end{array}$ & & \\
\hline G.Energy conversion & Motor & $\begin{array}{l}\text { Hydraulic } \\
\text { pump }\end{array}$ & $\begin{array}{l}\text { Air } \\
\text { compresso } \\
\mathrm{r}\end{array}$ & & \\
\hline $\begin{array}{l}\text { H.Energy transfer and } \\
\text { distribution }\end{array}$ & Gear box & Chain drive & Belt drive & & \\
\hline
\end{tabular}

According to the morphological matrix, a system solution is obtained by selecting one out of each functional element of the sub function to be organically combined. 


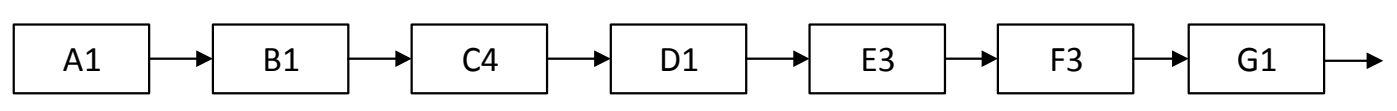

Figure 6. Assembly diagram

The device adopts wheel structure through the internal and external side wheel speed difference turns. Pure mechanical clamping is adopted along the entire working process, which ensures the delivery of wheeled crawling friction while ensuring locked in place. The device adopts a scrubbing cleaning mode. The device is controlled by a signal acquisition device and driven by motor.

\section{Structural Design}

The main body of the lamp pole cleaning device intend to adopts an upper and lower ring structure which is connected by a ball hinge joint. The upper ring is used to drive and the lower ring is used to scrub. The driving ring adopts a wheel structure, and the mechanical characteristics of the spring can ensure the clamping force of the device on the street lamp pole and the friction force required by the wheel walking. The scrubbing ring also presses the scrubbing cloth on the surface of the lamp rod through a pressure spring. The utility model has the advantages that the device can adapt to the lamp poles with different diameters and different diameters. Ball hinge allows the upper ring to drive the lower ring to turn, and can swing to adapt to the turning angle. It's easy for the ring structure to be disassembled, which makes it conveniently installing the device on the lamp pole.

Table 2 Functional module

\begin{tabular}{|c|c|c|}
\hline Module Division & $\begin{array}{l}\text { Composing } \\
\text { Mechanisms }\end{array}$ & Main Function \\
\hline $\begin{array}{l}\text { Driving } \\
\text { device(the driving } \\
\text { ring) }\end{array}$ & $\begin{array}{l}\text { Motor, driving ring, } \\
\text { friction wheel }\end{array}$ & $\begin{array}{l}\text { Driving the driving ring movement on the } \\
\text { surface of light pole.Friction wheel can } \\
\text { holds the clamping effect to ensure the } \\
\text { stability of the device. }\end{array}$ \\
\hline $\begin{array}{l}\text { Cleaning device } \\
\text { (the scrubbing } \\
\text { ring) }\end{array}$ & $\begin{array}{l}\text { scrubbing cloth, nozzle, } \\
\text { pipe }\end{array}$ & $\begin{array}{l}\text { The pipeline transports water and } \\
\text { detergent to the cleaning place and the } \\
\text { water is sprayed by nozzle. When the } \\
\text { device is moving, the cloth pressed on the } \\
\text { surface of the lamp pole is scrubbing. }\end{array}$ \\
\hline Turning device & $\begin{array}{l}\text { spherical hinge, support } \\
\text { frame }\end{array}$ & $\begin{array}{l}\text { The ball hinge is used to adjust the angle } \\
\text { between the upper and the lower rings wh } \\
\text { en they turns. The supporting frame separ } \\
\text { ates the two ring from a suitable distance } \\
\text { to avoid interference when turning. }\end{array}$ \\
\hline $\begin{array}{c}\text { Intensifying } \\
\text { device }\end{array}$ & $\begin{array}{l}\text { Spring, sliding sleeve, } \\
\text { framework }\end{array}$ & $\begin{array}{l}\text { One end of the spring is stuck on the } \\
\text { frame, and the other end is connected to } \\
\text { the sleeve (or scrubbing cloth). Sleeve can } \\
\text { move on the framework, spring is in a } \\
\text { compressed state of the whole process } \\
\text { that device works in street light pole. }\end{array}$ \\
\hline
\end{tabular}




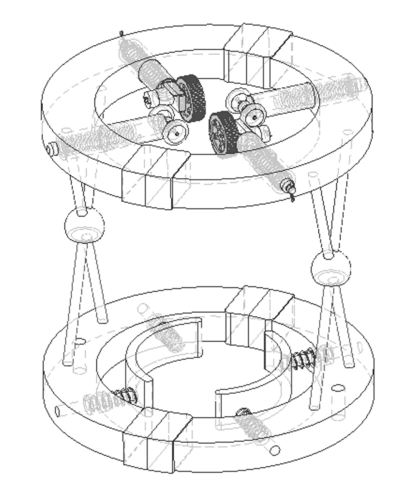

Figure 7. Conceptual design

This conceptual design of street light pole automatic cleaning device focus mainly on innovation, and it shows specifically in:

A. Ring structure concise of up and down, flexible, easy to split or install;

B. Using spherical hinge as turning member, simple and easy. It can drive totally by driving wheel while not need others power of turning;

C. Changing the route of climbing by adjust the angel between wheel and light pole, adjusting the force of cleaning.

D. The way of transporting water and detergent in pipe, simplifying the device, reducing the weight.

\section{Reference}

[1] Chen Mingsen. Research on motion principle and dynamics of climbing pole robot [D]. Wuhan University of Technology, 2009.

[2] Fu Yi Li, Li Zhihai. Research progress of wall climbing robot [J]. Mechanical design, 2008, 25 (4): $1-5$.

[3] Zhao Songnian, Li Enguang. Analysis and design of modern mechanical products [M]. Machinery Industry Press, 1900.

[4] Yu Fusheng, Su Xiaoqing, Shen Xiaoqin, etc. A pneumatic climbing pole robot: CN200957564 [P]. 2007.

[5] Luo Jie. Pipeline climbing robot structure design and driving dynamic characteristics analysis [D]. Wuhan University of Science and Technology, 2015.

[6] Wu Gongping, Xiao Xiaohui, Guo Yinglong, etc. Development of automatic crawling robot for overhead high voltage transmission line [J]. China Mechanical Engineering, 2006, 17 (3): 237-240.

[7] Prassler E, Ritter A, Schaeffer C, et al. A Short History of Cleaning Robots[J]. Autonomous Robots, 2000, 9(3):211-226.

[8] Zhou Lifun, Liu Hongzhao, Li Yue. Overview on the Current Situation and Key Technology of Cleaning Robot [J]. Mechanical Science and Technology, 2014, 33 (5): 635-642.

[9] Deng Xia. Research of arge-scale condenser cleaning robot's virtual reality teleoperation system [D]. Hunan University, 2009.

[10] Wang Wei. Smart gripping robot related issues [D]. Beijing University of Aeronautics and Astronautics, 2000.

[11] Wu Ruomei, Ceng Kejian. Design of mechanical products based on black-box and gray-box theory [J]. Packaging engineering, 2002, 23 (): 9-10. 